\title{
Article \\ Effects of Dry Needling in Teres Major Muscle in Elite Handball Athletes. A Randomised Controlled Trial
}

\author{
Luis Ceballos-Laita ${ }^{1}{ }^{*}$, Ricardo Medrano-de-la-Fuente ${ }^{1}$, Elena Estébanez-De-Miguel ${ }^{2}$, Jorge Moreno-Cerviño ${ }^{1}$, \\ María Teresa Mingo-Gómez ${ }^{1}$, Ignacio Hernando-Garijo ${ }^{1}$ (D) and Sandra Jiménez-del-Barrio ${ }^{1}$ \\ 1 Department of Surgery, Ophthalmology, Otorhinolaryngology and Physiotherapy, Faculty of Health Sciences, \\ University of Valladolid, 42004 Soria, Spain; ricardo.medrano@uva.es (R.M.-d.-1.-F.); \\ jorgemorenocer@gmail.com (J.M.-C.); tmingo@cir.uva.es (M.T.M.-G.); ignacio.hernando@uva.es (I.H.-G.); \\ sandra.jimenez.barrio@uva.es (S.J.-d.-B.) \\ 2 Department of Physiatrist and Nursey, Faculty of Health Sciences, University of Zaragoza, 50010 Zaragoza, \\ Spain; elesteba@unizar.es \\ * Correspondence: luis.ceballos@uva.es
}

Citation: Ceballos-Laita, L.; Medrano-de-la-Fuente, R.; Estébanez-De-Miguel, E.; Moreno-Cerviño, J.; Mingo-Gómez, M.T.; Hernando-Garijo, I.; Jiménez-del-Barrio, S. Effects of Dry Needling in Teres Major Muscle in Elite Handball Athletes. A Randomised Controlled Trial. J. Clin. Med. 2021, 10, 4260. https:// doi.org/10.3390/jcm10184260

Academic Editor: Tomasz Halski

Received: 31 August 2021

Accepted: 17 September 2021

Published: 20 September 2021

Publisher's Note: MDPI stays neutra with regard to jurisdictional claims in published maps and institutional affiliations.

Copyright: (c) 2021 by the authors. Licensee MDPI, Basel, Switzerland. This article is an open access article distributed under the terms and conditions of the Creative Commons Attribution (CC BY) license (https:// creativecommons.org/licenses/by/ $4.0 /)$.

\begin{abstract}
Objective: To determine the effects of dry needling (DN) in active myofascial trigger points in the teres major muscle compared to an untreated control group in pain during throwing actions, shoulder range of motion (ROM), strength, and extensibility of the tissues in professional handball (HB) athletes. Methods: A randomised, single-blinded, controlled clinical trial was designed. Thirty HB athletes with shoulder pain were randomly assigned to the DN group $(n=15)$ or control group $(n=15)$. The DN group received a single session of ultrasound-guided DN technique in the teres major muscle. The control group received no intervention. Pain intensity during throwing actions (Numeric Pain Rating Score), shoulder ROM (inclinometer), isometric strength (hand-held dynamometer), and extensibility (inclinometer) were measured before and after treatment. Results: DN group showed statistically significant improvements with large effect sizes for pain intensity $(p<0.001$; E.S: 1.3$)$, internal rotation ROM ( $p<0.001$; E.S: 3.0$)$ and extensibility ( $p<0.001$; E.S: 2.9$)$ compared to the control group. No statistically significant differences were found for isometric strength $(p>0.05)$. Conclusion: A single session of $\mathrm{DN}$ in the teres major muscle was effective for improving pain intensity during throwing actions, internal rotation ROM and extensibility in HB athletes with shoulder pain.
\end{abstract}

Keywords: shoulder pain; myofascial pain syndrome; trigger point; dry needling

\section{Introduction}

Handball (HB) is a popular sport, with more than 27 million athletes around the world [1]. This sport involves a wide variety of throwing actions in which the shoulder is exposed to large demands due to repeated overhead motion at high velocity [2,3]. These repeated movements provoke symptoms of overuse injuries. Recent studies have reported that the prevalence of acute or chronic shoulder pain among $\mathrm{HB}$ athletes ranges from $36 \%$ to $44.2 \%[4,5]$.

Previous authors have studied several adaptable risk factors in HB athletes with shoulder pain. Cinematic studies have shown a reduction in the glenohumeral internal rotation range of motion ( $\mathrm{ROM})$ and an increment in the external rotation $\mathrm{ROM}$ in the throwing shoulder (TS) compared to the contralateral shoulder (non-TS) [6-8]. Athletes with glenohumeral internal rotation deficit (GIRD) and external rotation gain (ERG) have presented a higher risk of suffering shoulder pain. The GIRD is currently considered a primary risk factor in the development of shoulder injuries [6,7,9-14].

Different authors discussed that these glenohumeral ROM changes occur because of the restriction of the posteroinferior capsule and the posterior band of the inferior glenohumeral ligament $[7,10]$ and because of the stiffness of the posterior shoulder muscles [15]. 
The restriction of the different tissues of the posteroinferior part of the shoulder shift the humeral head center of rotation to posterosuperior [7,10]. Therefore, the shift of the humeral head generates an attenuation of the anterior part of the capsule and ligaments of the TS, causing different injuries, such as anterior instability, labrum injuries or shoulder impingements $[6,7,9-13]$. However, a recent study suggested a new paradigm in the shoulder complex [16]. The teres major muscle seems to be an additional component in the glenohumeral stability. This muscle also resists the inferior displacement of the humeral head when the arm is being lifted [16]. So, its dysfunction due to the repetitive movements at high velocity, could be related to glenohumeral ROM changes.

The pain and the changes in glenohumeral ROM in HB athletes could be related to the presence of myofascial trigger points (MTrPs) in the teres major muscle. Active MTrPs are hyperirritable spots in a palpable taut band that cause spontaneous pain, referred pain, restricted ROM and muscle weakness [17]. The pain described by Travell and Simons for active MTrPs in the teres major muscle is similar to the shoulder pain described by $\mathrm{HB}$ athletes [18].

Dry needling $(\mathrm{DN})$ is an invasive technique that has shown grade A evidence of the treatment of MTrPs in the upper quarter [19]. This treatment consists of the introduction of a needle into the MTrPs [20]. DN has been shown to be effective in reducing pain intensity for nontraumatic shoulder pain [21,22]. However, the effects of DN in the teres major muscle has not been investigated in HB athletes with shoulder pain.

The aim of the current study was to determine the immediate effects of DN therapy in the active MTrPs of the teres major muscle in HB athletes with shoulder pain in pain intensity, glenohumeral ROM, isometric strength and extensibility of the tissues of the posterior part of the shoulder.

\section{Materials and Methods}

\subsection{Study Design and Ethical Approval}

A randomised single-blind controlled clinical trial was carried out between February and April 2021. The study design followed the Consolidated Standards of Reporting Trials (CONSORT) Guidelines. The study was registered at www.clinicaltrials.gov (accessed on 25 February 2021) and obtained the identification number NCT04777578. The Clinical Research Ethics Committee of Valladolid Este approved the study (CASVE-NM-21-504). The participants provided written and signed informed consent to participate in the study.

\subsection{Sample Size}

The sample size was calculated based on the primary outcome (pain intensity) using the Minitab 13.0 program. A value of 2.17 in the Numeric Pain Rating Score (NPRS) has been reported as the minimum clinically important difference (MCID) for shoulder pain [23] for the between-groups mean value. The standard deviation was based on a pilot study with $\mathrm{HB}$ athletes. Assuming a between-group mean value of 2.17 points and a standard deviation of 2.43 and estimating a two-tail test a level of significance of 0.05 and a follow-up loss rate of $15 \%, 30$ participants were necessary for both groups (15 participants per group).

\subsection{Participants}

Thirty male patients (mean age $22.39 \pm 3.73$ years) were recruited from elite professional HB clubs in Soria (Spain).

The inclusion criteria were: male with unilateral shoulder pain and reproducible during throwing actions, 18-30 years of age, a minimum of 2 years' experience practicing $\mathrm{HB}$, practice routine of a minimum of $2 \mathrm{~h} / \mathrm{d}$ and $3 \mathrm{~d} / \mathrm{w}$, a GIRD value $\geq 15^{\circ}$ [12] and presence of an active MTrP in the teres major muscle. The identification of $\mathrm{MTrP}$ was performed using manual palpation. Manual palpation is the current criterion standard and has been shown to be reliable for the identification of MTrPs in the upper limb muscles [24]. The Travell and Simons criteria were used to identify the presence of MTrPs [18]: 
(1) presence of a palpable taut band; (2) appearance of local and/or referred pain when pressing the nodule of the taut band; and (3) recognition of the pain by the patient.

The exclusion criteria were: previous fracture, dislocation or surgery in any joint of the upper limb, cervical spine or thoracic spine, use of analgesics, muscle relaxants or other pharmacological treatment, previous physiotherapy treatment in the last month and DN contraindications (e.g., fear of needles).

\subsection{Randomization and Masking}

Thirty HB athletes were randomly allocated to both groups: the DN group or the control group. An independent assistant allocated the participants to the groups (ratio 1:1) using the GraphPad computer software 2018 (GraphPad Software, San Diego, CA, USA).

\subsection{Interventions}

DN intervention was performed by an experienced physical therapist with more than 7 years of clinical experience in the treatment of MTrPs with DN therapy. The intervention was ultrasound-guided to ensure the treatment of the targeted muscle. The therapist who applied the ultrasound had more than 10 years of experience in musculoskeletal sonography. Both therapists were blinded to all the measurements.

Participants allocated to the DN group received a single session of DN guided by ultrasound (SmartUS EXT-1M, REV:C; TELEMED, Lithuania, Vilnius, Lithuania) into active MTrPs in the teres major muscle. The active MTrP in the teres major muscle, that reproduced the symptoms of the patient, was treated. The ultrasound-guided technique provided a precise needle location within the teres major muscle, increasing the efficacy of treatment and minimizing risks. The transducer was first placed from the inferior angle of the scapula following the direction of the teres major muscle. The patient was lying in a prone position, and a $0.30 \mathrm{~mm} \times 50 \mathrm{~mm}$ single-use stainless needle was inserted through the skin beside the ultrasound transducer using a guide tube [18].

Hong's fast-in fast-out technique $[25,26]$ was performed with the aim of eliciting the local twitch response. The quick contraction of the local muscle fibers in response to mechanical stimulation was detected by ultrasound visualization. The needle was repeatedly inserted until the local twitch responses became extinct [27]. A cotton ball was used to perform haemostasis and prevent bleeding after removing the needle.

No additional intervention was applied to the participants assigned to the control group. The participants remained in prone position for the same time that the intervention lasted in the DN group.

\subsection{Outcomes}

Outcome variables were measured at baseline and immediately after the intervention by two blinded examiners. Sociodemographic and clinical data were registered prior to testing. Pain intensity was the primary outcome, and passive ROM, isometric strength and extensibility of the posterior part of the shoulder were the secondary outcomes.

\subsubsection{Pain Intensity}

Pain intensity during throwing action was recorded using the 11-point NPRS, in which 0 represented "no pain" and 10 "the most intense pain imaginable". The reliability of the NPRS is good (Intraclass Correlation Coefficient (ICC) $2,1=0.71-0.88$ ) [28].

\subsubsection{Passive Range of Motion}

The passive internal and external rotation ROM were recorded using a digital inclinometer following the procedure described by Fieseler et al. [29]. The patient was placed in a supine position with the shoulder at $90^{\circ}$ of abduction and a towel under the arm to ensure the correct alignment of the upper limb in the frontal plane. The digital inclinometer was placed on the ventral part of the forearm, and the scapula was stabilized manually by the examiner. The internal and external rotation ROM was registered when the scapula 
was felt to move. The reliability of this protocol has been shown to be good for internal and external rotation (internal rotation: $\mathrm{ICC}_{2,1}=0.79(0.52-0.91)$; external rotation: $\mathrm{ICC}_{2,1}=0.76$ (0.48-0.89) [30]. In a preliminary intratester reliability, the ICC values obtained for these measurements were 0.88 for internal rotation and 0.90 for external rotation. Both shoulder joints (TS and non-TS) were measured.

After the passive ROM measurements, the GIRD and the ERG were calculated. The GIRD is considered the difference in internal rotation between the TS and the non-TS, described in negative value. The ERG is considered the difference in external rotation between both shoulder joints, described in positive value $[29,30]$.

\subsubsection{Muscle Strength}

The maximum isometric strength was measured following the procedure described by Romero-Franco et al. [31] using a hand-held dynamometer Lafayette model 01165 . The patient was placed in the same position as described in the passive ROM measurement. The hand-held dynamometer was placed on the ventral part of the forearm or on the dorsal part of the forearm to assess internal rotation or external rotation isometric strength, respectively. The reliability of this protocol has been shown to be excellent for internal and external rotation (internal rotation: ICC $_{2,1}=0.99(0.97-0.99)$; external rotation: ICC $_{2,1}=0.99$ (0.98-0.99) [31]. Three trials were performed, and the maximum isometric force was taken. The ICC values achieved in a preliminary intratester reliability study were 0.96 for both measurements.

\subsubsection{Extensibility}

The extensibility of the tissues of the posterior part of the shoulder was assessed using a digital inclinometer, according to the protocol described by Tyler et al. [32,33]. The patient was placed in side-lying position with the shoulder at $90^{\circ}$ of abduction. The examiner manually stabilized the scapula. The angle was registered situating the digital inclinometer on the distal part of the humerus. If the humerus was horizontal, it was considered $0^{\circ}$; if below (adducted), it was recorded as a positive number; if above the horizontal (abducted), it was recorded as a negative number. This protocol has shown an excellent reliability $\left.(\mathrm{ICC})_{2,1}=0.92\right)[32,33]$. The ICC value obtained in a preliminary intratester reliability study was 0.95 .

Primary and secondary outcome variables were measured before training sessions or warm-up.

\subsection{Statistical Analysis}

We performed statistical analyses using SPSS, version 20.0 for Windows. A $p$-value $<0.05$ was considered statistically significant. Descriptive statistics were calculated to describe the sample. The Shapiro-Wilk test was used to calculate the normal distribution of the variables. The student's t-test or the Mann-Whitney $U$ test were used to compare demographic and clinical variables at baseline between both groups, according to the normally distributed data or non-normally distributed data, respectively. The chi-squared test or Fisher exact test were used to compare categorical data depending on the normality or non-normality distribution.

The Group by Time interaction between both groups (DN group and Control group) and time points (baseline and postintervention) were calculated using a two-way analysis of variance (ANOVA). The effect size (Cohen's d) was also calculated to estimate the magnitudes of the within-group differences. The magnitude of the difference was classified as small if the value of Cohen's $\mathrm{d}$ ranged from 0.2 to 0.5 ; as moderate if it ranged from 0.5 to 0.8; and as large if Cohen's $d$ was greater than 0.8. Moderate and large magnitudes of effect size were considered indicators of appropriate statistical power [34].

\section{Results}

Between February and April 2020, 35 HB athletes with shoulder pain were screened for eligibility. Five $\mathrm{HB}$ athletes were not included for having received surgical interventions 
or physiotherapy treatment in the last month. No HB athletes were excluded for not presenting an MTrP in the teres major muscle. Finally, thirty HB athletes met all the eligibility criteria and were randomised to the DN group $(n=15)$ or to the control group $(n=15)$. The flowchart of the study is presented in Figure 1.

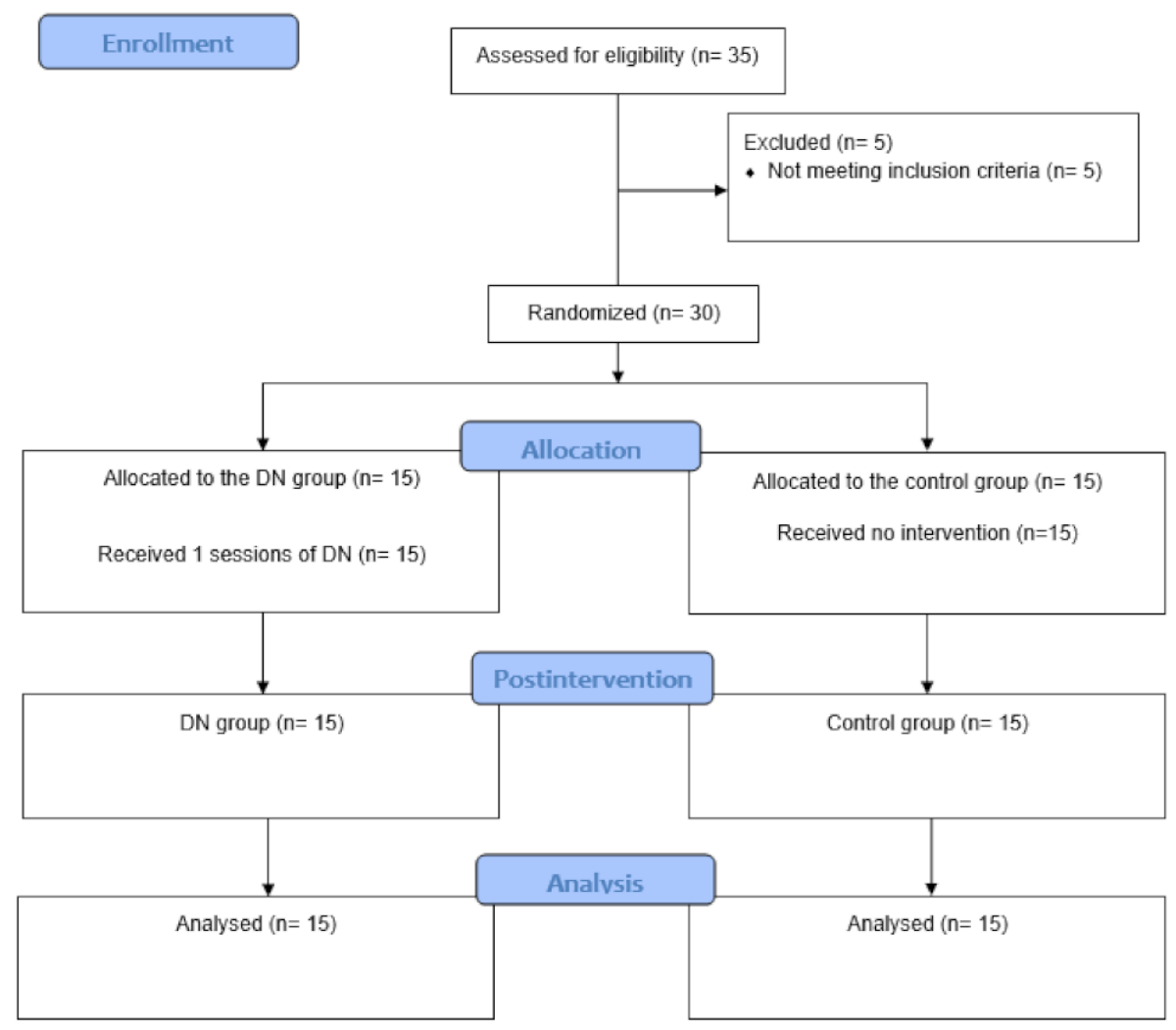

Figure 1. Flowchart diagram.

Sociodemographic and clinical characteristics of the HB athletes included are reported in Table 1 . No statistically significant differences were found at baseline between both groups for any of the sociodemographic or clinical variables $(p>0.05)$.

Table 1. Sociodemographic and clinical outcomes.

\begin{tabular}{cccc}
\hline Outcomes & DN Group & Control Group & $p$-Value \\
\hline Age $($ years $)$ & $22.47(3.04)$ & $22.31(4.37)$ & $\mathrm{U}=106.50 ; p=0.591$ \\
Height $(\mathrm{cm})$ & $182.20(9.21)$ & $186.25(6.99)$ & $\mathrm{F}=1.91 ; p=0.177$ \\
Weight $(\mathrm{Kg})$ & $80.33(10.80)$ & $85.56(11.52)$ & $\mathrm{F}=1.69 ; p=0.203$ \\
BMI $\left(\mathrm{Kg} / \mathrm{cm}^{2}\right)$ & $24.17(2.57)$ & $24.64(2.80)$ & $\mathrm{F}=0.22 ; p=0.637$ \\
NPRS & $3.96(2.20)$ & $3.56(2.84)$ & $\mathrm{U}=101.00 ; p=0.894$ \\
IR ROM $\left(^{\circ}\right)$ & $22.00(6.49)$ & $25.78(5.65)$ & $\mathrm{F}=3.00 ; p=0.109$ \\
ER ROM $\left(^{\circ}\right)$ & $95.60(10.54)$ & $98.03(6.21)$ & $\mathrm{F}=0.62 ; p=0.437$ \\
GIRD $\left(^{\circ}\right)$ & $-25.63(8.9)$ & $-25.46(8.13)$ & $\mathrm{F}=0.01 ; p=0.958$ \\
ERG $\left(^{\circ}\right)$ & $8.43(7.68)$ & $5.40(12.42)$ & $\mathrm{F}=0.65 ; p=0.425$ \\
IR strength $(\mathrm{Kg})$ & $13.06(1.96)$ & $13.93(2.99)$ & $\mathrm{F}=0.88 ; p=0.353$ \\
ER strength $(\mathrm{Kg})$ & $16.52(3.98)$ & $16.25(3.58)$ & $\mathrm{F}=0.03 ; p=0.844$ \\
Extensibility $\left(^{\circ}\right)$ & $-14.43(6.73)$ & $-13.34(4.76)$ & $\mathrm{F}=0.27 ; p=0.605$ \\
\hline DN: Dry Needling; $\mathrm{NPRS}:$ Numeric Pain Rating Score $\mathrm{IR} \cdot$ Internal Rotation; ER: External Rotation; ROM:
\end{tabular}

DN: Dry Needling; NPRS: Numeric Pain Rating Score; IR: Internal Rotation; ER: External Rotation; ROM: Range of Motion; GIRD: Glenohumeral Internal Rotation Deficit; ERG: External Rotation Gain.

A two-way ANOVA showed a significant Group by Time interaction after the intervention for pain intensity $(\mathrm{F}=21.72 ; p<0.001)$, internal rotation $\mathrm{ROM}(\mathrm{F}=102.70 ; p<0.001)$, external rotation $\operatorname{ROM}(\mathrm{F}=5.57 ; p=0.025), \mathrm{GIRD}(\mathrm{F}=80.50 ; p<0.001), \mathrm{ERG}(\mathrm{F}=5.57 ; p=0.025)$ 
and extensibility $(\mathrm{F}=53.32 ; p<0.001)$. The $\mathrm{DN}$ group presented higher changes than the control group in pain intensity $(\Delta 2.40$ (0.92 to 3.88), internal rotation ROM $(\Delta-18.86(-23.40$ to $-14.31)$, external rotation $\operatorname{ROM}(\Delta 10.05$ (3.36 to -16.74$)$, GIRD $(\Delta-23.72(-30.25$ to -17.18$)$, $\operatorname{ERG}(\Delta 4.60(-4.79$ to 13.99$)$ and extensibility $(\Delta-15.16(-10.03$ to -11.29$)$. No betweengroups or within-groups differences were found for maximum isometric strength $(p>0.05)$. Table 2 provides before and after treatment session data, within-group and between-groups differences and effect sizes.

Table 2. Baseline and postintervention outcomes as well as within group changes.

\begin{tabular}{|c|c|c|c|c|c|c|}
\hline Outcomes & $\begin{array}{c}\text { Baseline } \\
\text { Mean (SD) }\end{array}$ & $\begin{array}{l}\text { Postintervention } \\
\text { Mean (SD) }\end{array}$ & $\begin{array}{l}\text { Within-Group } \\
\text { Changes }\end{array}$ & Effect Size & $\begin{array}{c}\text { Between-Groups } \\
p \text {-Values }\end{array}$ & Effect Size \\
\hline \multicolumn{7}{|l|}{ Pain intensity } \\
\hline DN group & $3.96(2.20)$ & $0.65(0.71)$ & \multirow{2}{*}{$\begin{array}{c}-3.30(2.02,4.59) \\
p<0.001 \\
-0.50(-0,05 \\
1.05) p=0.072\end{array}$} & 2.0 & \multirow[t]{2}{*}{$\begin{array}{l}\mathrm{F}=21.72 \\
p<0.001\end{array}$} & \multirow[t]{2}{*}{1.3} \\
\hline Control group & $3.56(2.84)$ & $3.06(2.50)$ & & 0.1 & & \\
\hline \multicolumn{7}{|l|}{$\operatorname{IR~ROM}\left(^{\circ}\right)$} \\
\hline DN group & $22.00(6.49)$ & $45.26(6.54)$ & \multirow{2}{*}{$\begin{array}{c}23.26(-28.12 \\
-18.40) p<0.001 \\
0.62(-1.53,0.28) \\
p=0.164\end{array}$} & 3.5 & \multirow[t]{2}{*}{$\begin{array}{c}\mathrm{F}=102.70 \\
p<0.001\end{array}$} & \multirow[t]{2}{*}{3.0} \\
\hline Control group & $25.78(5.65)$ & $26.40(5.82)$ & & 0.1 & & \\
\hline \multicolumn{7}{|l|}{ ER ROM $\left(^{\circ}\right)$} \\
\hline DN group & $95.60(10.54)$ & 89.06 (11.07) & \multirow{2}{*}{$\begin{array}{c}-6.53(-0.41 \\
13.48) p=0.063 \\
1.09(-2.69,0.50) \\
p=0.166\end{array}$} & 0.6 & \multirow[t]{2}{*}{$\mathrm{F}=5.57 ; p=0.025$} & \multirow[t]{2}{*}{1.0} \\
\hline Control group & $98.03(6.21)$ & 99.12 (6.75) & & 0.1 & & \\
\hline \multicolumn{7}{|l|}{$\operatorname{GIRD}\left(^{\circ}\right)$} \\
\hline DN group & $-25.63(8.9)$ & $-2.50(9.03)$ & \multirow{2}{*}{$\begin{array}{c}23.13(-27.96 \\
-18.30) p<0.001 \\
-0.75(-2.40 \\
3.90) p=0.619\end{array}$} & 2.5 & \multirow[t]{2}{*}{$\begin{array}{l}\mathrm{F}=80.50 \\
p<0.001\end{array}$} & \multirow[t]{2}{*}{2.6} \\
\hline Control group & $-25.46(8.13)$ & $-26.21(8.75)$ & & 0.1 & & \\
\hline \multicolumn{7}{|l|}{$\mathrm{ERG}\left({ }^{\circ}\right)$} \\
\hline DN group & $8.43(7.68)$ & $1.90(13.11)$ & \multirow{2}{*}{$\begin{array}{c}-6.53(-0.41 \\
13.48) p=0.063 \\
1.09(-2.69,0.50) \\
p=0.166\end{array}$} & 0.6 & \multirow[t]{2}{*}{$\mathrm{F}=5.57 ; p=0.025$} & \multirow[t]{2}{*}{0.3} \\
\hline Control group & $5.40(12.42)$ & $6.50(12.44)$ & & 0.1 & & \\
\hline \multicolumn{7}{|l|}{$\begin{array}{l}\text { IR Strength } \\
(\mathrm{Kg})\end{array}$} \\
\hline DN group & $13.06(1.96)$ & $13.51(2.69)$ & \multirow{2}{*}{$\begin{array}{c}0.44(-1.53,0.63) \\
p=0.392 \\
0.25(-0.78,0.27) \\
p=0.321\end{array}$} & 0.1 & \multirow[t]{2}{*}{$\mathrm{F}=0.11 ; p=0.773$} & \multirow[t]{2}{*}{0.2} \\
\hline Control group & $13.93(2.99)$ & $14.18(2.80)$ & & 0.1 & & \\
\hline \multicolumn{7}{|l|}{$\begin{array}{l}\text { ER Strength } \\
(\mathrm{Kg})\end{array}$} \\
\hline DN group & $16.52(3.98)$ & $17.27(4.35)$ & \multirow{2}{*}{$\begin{array}{c}0.75(-1.85,0.35) \\
p=0.165 \\
0.63(-1.99,0.73) \\
p=0.339\end{array}$} & 0.1 & \multirow[t]{2}{*}{$\mathrm{F}=0.02 ; p=0.884$} & \multirow[t]{2}{*}{0.1} \\
\hline Control group & $16.25(3.58)$ & $16.88(4.34)$ & & 0.1 & & \\
\hline \multicolumn{7}{|l|}{ Extensibility $\left({ }^{\circ}\right)$} \\
\hline DN group & $-14.43(6.73)$ & $-0.8(3.78)$ & \multirow{2}{*}{$\begin{array}{c}13.63(-17.19 \\
-10.07) p<0.001 \\
-2.62(-0.55 \\
5.80) p=0.099\end{array}$} & 2.5 & \multirow[t]{2}{*}{$\begin{array}{l}\mathrm{F}=53.32 \\
p<0.001\end{array}$} & \multirow[t]{2}{*}{2.9} \\
\hline Control group & $-13.34(4.76)$ & $-15.96(6.34)$ & & 0.4 & & \\
\hline
\end{tabular}

SD: Standard Deviation; DN: Dry Needling; NPRS: Numeric Pain Rating Score; IR: Internal Rotation; ER: External Rotation; ROM: Range of Motion; GIRD: Glenohumeral Internal Rotation Deficit; ERG: External Rotation Gain. 


\section{Discussion}

To the best of our knowledge, this is the first study to investigate the short-term effects of $\mathrm{DN}$ in the teres major muscle in $\mathrm{HB}$ athletes with shoulder pain. This randomised controlled trial showed that a single session of DN in the teres major muscle decreased pain during throwing actions, improved internal rotation ROM, GIRD and the extensibility of the tissues of the posterior part of the shoulder.

Pain intensity during the throwing action decreased after DN treatment. The change achieved in the DN group was higher than the MCID stated for patients with shoulder pain (2.17) [23]. These results are in agreement with previous studies that reported that one to three sessions of DN therapy in the infraspinatus muscle and upper trapezius muscle decreased pain intensity in the short-term in patients with shoulder pain [21,35]. However, this is the first study that investigated the effects of a single session of DN in the teres major muscle.

The analgesic effects may be related to the introduction of the needle into the dysfunctional motor endplate of the MTrP. DN therapy enhances the secretion of endogenous opioids, producing an immediate drop of proinflammatory cytokines and interleukins, neurotransmitters and neuromodulators [36,37].

Concerning shoulder ROM, Fieseler et al. [29] and Almeida et al. [12] showed that $\mathrm{HB}$ athletes with shoulder pain presented a GIRD greater than $15^{\circ}$. The HB athletes with shoulder pain included in this study presented a mean GIRD of $-25.54^{\circ} \pm 8.38^{\circ}$ (DN group: $-25.63^{\circ} \pm 8.9^{\circ}$; Control group: $-25.46^{\circ} \pm 8.13^{\circ}$ ). Therefore, the results reported in the current study at baseline are in agreement with previous studies that investigated the risk factors in HB athletes [12,29].

After the DN treatment, the internal rotation ROM increased, and the GIRD decreased. The mean values achieved on internal rotation ROM and GIRD were similar to the values reported for HB athletes without shoulder pain [12,29]. Burkhart et al. [7,10] described that the GIRD and the ERG could be explained because the restriction of the capsule and the ligament of the shoulder change the center of rotation of the humeral head to posterosuperior. However, the results achieved in this study showed that the teres major could play an additional role with the capsule and ligament structures, and its treatment may reverse these glenohumeral adaptations.

The extensibility of the tissues of the posterior part of the shoulder improved after the intervention in the DN group. The restriction of the tissues of the posterior part of the shoulder seems to be related to the changes in glenohumeral ROM [7,10]. Manske et al. [15] showed that the stretching of the tissues of the posterior part of the shoulder improved the internal rotation ROM. Despite this fact, few studies in the literature assessed the extensibility in different sports that involve throwing actions. However, the extensibility assessment could be an interesting variable to consider among throwing athletes.

The improvements achieved in the extensibility test may be related to the introduction of the needle into the MTrP. The needle provokes a disruption in the muscle fibers and motor endplates among other structures. The destruction of the dysfunctional motor endplates and the shortened sarcomeres of the taut band may explain these results $[20,38]$.

Isometric maximum strength showed no between-groups or within-groups changes after the intervention. A recent meta-analysis suggested that DN has no effect on force production in patients with shoulder pain [39].

From a clinical viewpoint, the results reported in this randomised controlled trial showed that shoulder pain, internal rotation ROM, GIRD and the extensibility of the tissues of the posterior part of the shoulder in $\mathrm{HB}$ athletes seem to be linked to the presence of MTrPs in the teres major muscle. The intervention based on one single session of DN reported a statistically significant and clinically relevant decrease in pain intensity during throwing actions and an increase of internal rotation ROM, GIRD and extensibility of the tissues of the posterior part of the shoulder. According to these results, the treatment of the teres major muscle in $\mathrm{HB}$ athletes with shoulder pain may change pain intensity and reduce the primary risk factor for several injuries. 
Several limitations need to be considered. First, only male HB athletes were included; thus, the results cannot be generalized to female patients or other athletes. Second, just one session was applied, and the results were measured immediately after the intervention, so no medium- or long-term effects were evaluated. Third, the outcomes were achieved after DN therapy; however, the management of shoulder pain should be multidisciplinary. Finally, future studies should investigate the combination of DN with other techniques in the short-, medium- and long-term in different types of athletes with shoulder pain.

\section{Conclusions}

This study showed that pain during the throwing action decreased, glenohumeral internal rotation ROM increased and extensibility improved after a single session of DN in active MTrPs of the teres major muscle in HB athletes with shoulder pain.

Author Contributions: Conceptualization, L.C.-L., S.J.-d.-B. and E.E.-D.-M.; Methodology: L.C.-L., S.J.-d.-B., E.E.-D.-M. and R.M.-d.-1.-F.; Software: M.T.M.-G. and I.H.-G.; Formal analysis: S.J.-d.-B. and E.E.-D.-M.; Investigation: L.C.-L., S.J.-d.-B. and R.M.-d.-1.-F.; Writing: L.C.-L., R.M.-d.-1.-F., E.E.-D.-M., J.M.-C., M.T.M.-G., I.H.-G., S.J.-d.-B.; Writing-Review and Editing: L.C.-L., R.M.-d.-l.-F., E.E.-D.-M., J.M.-C., M.T.M.-G., I.H.-G., S.J.-d.-B.; Visualization and supervisión: S.J.-d.-B.; Project administration: L.C.-L. and J.M.-C. All authors have read and agreed to the published version of the manuscript.

Funding: This research received no external funding.

Institutional Review Board Statement: The study was conducted according to the guidelines of the Declaration of Helsinki, and approved by the Clinical Research Ethics Committee of Valladolid Este (protocol code CASVE-NM-21-504 February 15, 2021)" approved the study.

Informed Consent Statement: Informed consent was obtained from all subjects involved in the study.

Conflicts of Interest: The authors declare no conflict of interest.

\section{References}

1. Sporis, G.; Vuleta, D.; Milanović, D. Fitness profiling in handball: Physical and physiological characteristics of elite players. Coll. Antropol. 2010, 34, 1009-1014. [PubMed]

2. Kibler, W.B.; Kuhn, J.E.; Wilk, K.; Sciascia, A.; Moore, S.; Laudner, K.; Ellenbecker, T.; Thigpen, C.; Uhl, T. The disabled throwing shoulder: Spectrum of pathology-10-year update. Arthrosc. J. Arthrosc. Relat. Surg. 2013, 29, 141-161. [CrossRef] [PubMed]

3. Karcher, C.; Buchheit, M. On-Court demands of elite handball, with special reference to playing positions. Sport Med. 2014, 44, 797-814. [CrossRef] [PubMed]

4. Mohseni-Bandpei, M.A.; Keshavarz, R.; Minoonejhad, H.; Mohsenifar, H.; Shakeri, H. Shoulder Pain in Iranian Elite Athletes: The Prevalence and Risk Factors. J. Manip. Physiol. Ther. 2012, 35, 541-548. [CrossRef]

5. Myklebust, G.; Hasslan, L.; Bahr, R.; Steffen, K. High prevalence of shoulder pain among elite Norwegian female handball players. Scand. J. Med. Sci. Sport 2013, 23, 288-294. [CrossRef]

6. Wilk, K.E.; Macrina, L.C.; Fleisig, G.S.; Porterfield, R.; Ii, C.D.S.; Harker, P.; Paparesta, N.; Andrews, J.R. Correlation of Glenohumeral Internal Rotation Deficit and Total Rotational Motion to Shoulder Injuries in Professional Baseball Pitchers. Am. J. Sports Med. 2010, 39, 329-335. [CrossRef]

7. Burkhart, S.S.; Morgan, C.D.; Kibler, W. The disabled throwing shoulder: Spectrum of pathology part I: Pathoanatomy and biomechanics. Arthrosc. J. Arthrosc. Relat. Surg. 2003, 19, 404-420. [CrossRef]

8. Ceballos-Laita, L.; Pérez-Manzano, A.; Mingo-Gómez, T.; Hernando-Garijo, I.; Medrano-De-La-Fuente, R.; Estébanez-de-Miguel, E.; Barrio, J.D. Range of motion and muscle function on shoulder joints of young handball athletes. J. Back Musculoskelet. Rehabil. 2021, 1-7. [CrossRef]

9. Wilk, K.E.; Meister, K.; Andrews, J.R. Current Concepts in the Rehabilitation of the Overhead Throwing Athlete. Am. J. Sports Med. 2002, 30, 136-151. [CrossRef]

10. Burkhart, S.S.; Morgan, C.D.; Kibler, W.B. The disabled throwing shoulder: Spectrum of Pathology Part II: Evaluation and treatment of SLAP lesions in throwers. Arthrosc. J. Arthrosc. Relat. Surg. 2003, 19, 531-539. [CrossRef]

11. Seabra, P.; Van Eck, C.F.; Sá, M.; Torres, J. Are professional handball players at risk for developing a glenohumeral internal rotation deficit in their dominant arm? Phys. Sportsmed. 2017, 45, 77-81. [PubMed]

12. Almeida, G.P.L.; Silveira, P.F.; Rosseto, N.P.; Barbosa, G.; Ejnisman, B.; Cohen, M. Glenohumeral range of motion in handball players with and without throwing-related shoulder pain. J. Shoulder Elb. Surg. 2013, 22, 602-607. [CrossRef] [PubMed]

13. Tyler, T.F.; Nicholas, S.J.; Lee, S.J.; Mullaney, M.; McHugh, M.P. Correction of posterior shoulder tightness is associated with symptom resolution in patients with internal impingement. Am. J. Sports Med. 2010, 38, 114-119. [CrossRef] 
14. Keller, R.A.; De Giacomo, A.F.; Neumann, J.A.; Limpisvasti, O.; Tibone, J.E. Glenohumeral Internal Rotation Deficit and Risk of Upper Extremity Injury in Overhead Athletes: A Meta-Analysis and Systematic Review. Sports Health 2018, 10, 125-132. [CrossRef]

15. Manske, R.C.; Meschke, M.; Porter, A.; Smith, B.; Reiman, M. A Randomized Controlled Single-Blinded Comparison of Stretching Versus Stretching and Joint Mobilization for Posterior Shoulder Tightness Measured by Internal Rotation Motion Loss. Sports Health 2009, 2, 94-100. [CrossRef]

16. Barra-López, M.E.; López-de-Celis, C.; Pérez-Bellmunt, A.; Puyalto-de-Pablo, P.; Sánchez-Fernández, J.J.; Lucha-López, M.O. The supporting role of the teres major muscle, an additional component in glenohumeral stability? An anatomical and radiological study. Med. Hypotheses 2020, 141, 109728. [CrossRef]

17. Gerwin, R.D. Diagnosis of Myofascial Pain Syndrome. Phys. Med. Rehabil. Clin. 2014, 25, 341-355. [CrossRef]

18. Simons, D.; Travell, J.G.; Simons, L. Myofascial Pain and Dysfunction: The Trigger Point Manual, 2nd ed; Editorial Panamericana: Madrid, Spain, 2007; Volume 44.

19. Kietrys, D.M.; Palombaro, K.M.; Azzaretto, E.; Hubler, R.; Schaller, B.; Schlussel, J.M.; Tucker, M. Effectiveness of dry needling for upper-quarter myofascial pain: A systematic review and meta-analysis. J. Orthop. Sports Phys. Ther. 2013, 43, 620-634. [CrossRef]

20. Dommerholt, J.; Mayoral del Moral, O.; Gröbli, C. Trigger Point Dry Needling. J. Man. Manip. Ther. 2006, 14, 70E-87E. [CrossRef]

21. Kamali, F.; Sinaei, E.; Morovati, M. Comparison of Upper Trapezius and Infraspinatus Myofascial Trigger Point Therapy by Dry Needling in Overhead Athletes With Unilateral Shoulder Impingement Syndrome. J. Sport Rehabil. 2019, 28, 243-249. [CrossRef] [PubMed]

22. Navarro-Santana, M.J.; Gómez-Chiguano, G.F.; Cleland, J.A.; Arias-Buria, J.L.; Fernández-de-las-Peñas, C.; Plaza-Manzano, G. Effects of Trigger Point Dry Needling for Nontraumatic Shoulder Pain of Musculoskeletal Origin: A Systematic Review and Meta-Analysis. Phys. Ther. Rehabil. J. 2020, 101, 216.

23. Michener, L.A.; Snyder, A.R.; Leggin, B.G. Responsiveness of the Numeric Pain Rating Scale in Patients With Shoulder Pain and the Effect of Surgical Status. J. Sport Rehabil. 2011, 20, 115-128. [CrossRef] [PubMed]

24. Bron, C.; Franssen, J.; Wensing, M.; Oostendorp, R.A. Interrater Reliability of Palpation of Myofascial Trigger Points in Three Shoulder Muscles. J. Man. Manip. Ther. 2007, 15, 203-215. [CrossRef] [PubMed]

25. Hong, C.; Torigoe, Y. Electrophysiological characteristics of localized twitch responses in responsive taut bands of rabbit skeletal muscle fibers. J. Musculoskelet. Pain. 1994, 2, 17-43. [CrossRef]

26. Hong, C.-Z.; Torigoe, Y.; Yu, J. The Localized Twitch Responses in Responsive Taut Bands of Rabbit Skeletal Muscle Fibers Are Related to the Reflexes at Spinal Cord Level. J. Musculoskelet. Pain 1995, 3, 15-33. [CrossRef]

27. Ceballos-Laita, L.; Jiménez-del-Barrio, S.; Marín-Zurdo, J.; Moreno-Calvo, A.; Marín-Boné, J.; Albarova-Corral, M.I.; Estébanezde-Miguel, E. Effectiveness of Dry Needling Therapy on Pain, Hip Muscle Strength and Physical Function in Patients With Hip Osteoarthritis: A Randomized Controlled Trial. Arch. Phys. Med. Rehabil. 2021, 102, 959-966. [CrossRef]

28. Jensen, M.P.; Turner, J.A.; Romano, J.M.; Fisher, L.D. Comparative reliability and validity of chronic pain intensity measures. Pain 1999, 83, 157-162. [CrossRef]

29. Fieseler, G.; Jungermann, P.; Koke, A.; Irlenbusch, L.; Delank, K.S.; Schwesig, R. Range of motion and isometric strength of shoulder joints of team handball athletes duringthe playing season, part II: Changes after midseason. J. Shoulder Elb. Surg. 2015, 24, 391-398. [CrossRef]

30. Fieseler, G.; Jungermann, P.; Koke, A.; Irlenbusch, L.; Delank, K.S.; Schwesig, R. Glenohumeral range of motion (ROM) and isometric strength of professional team handball athletes, part III: Changes over the playing season. Arch. Orthop. Trauma Surg. 2015, 135, 1691-1700. [CrossRef]

31. Romero-Franco, N.; Fernández-Domínguez, J.C.; Montaño-Munuera, J.A.; Romero-Franco, J.; Jiménez-Reyes, P. Validity and reliability of a low-cost dynamometer to assess maximal isometric strength of upper limb: Low cost dynamometry and isometric strength of upper limb. J. Sports Sci. 2019, 37, 1787-1793. [CrossRef]

32. Tyler, T.F.; Roy, T.; Nicholas, S.J.; Gleim, G.W.; Davies, G.J.; Wilk, K.E.; Ellenbecker, T. Reliability and Validity of a New Method of Measuring Posterior Shoulder Tightness. J. Orthop. Sports Phys. Ther. 1999, 29, 262-274. [CrossRef] [PubMed]

33. Tyler, T.F.; Nicholas, S.J.; Roy, T.; Gleim, G.W. Quantification of posterior capsule tightness and motion loss in patients with shoulder impingement. Am. J. Sports Med. 2000, 28, 668-673. [CrossRef]

34. Cohen, J. Statistical Power Analysis for the Behavioral Sciences; Hillsdale, N.J., Ed.; Lawrence Erlbaum Associates Publishers: Mahwah, NJ, USA, 1988.

35. Calvo-Lobo, C.; Pacheco-da-Costa, S.; Martínez-Martínez, J.; Rodríguez-Sanz, D.; Cuesta-Álvaro, P.; López-López, D. Dry Needling on the Infraspinatus Latent and Active Myofascial Trigger Points in Older Adults With Nonspecific Shoulder Pain. J. Geriatr. Phys. Ther. 2018, 41, 1-13. [CrossRef] [PubMed]

36. Shah, J.P.; Danoff, J.V.; Desai, M.J.; Parikh, S.; Nakamura, L.Y.; Phillips, T.M.; Gerber, L.H. Biochemicals Associated With Pain and Inflammation are Elevated in Sites Near to and Remote From Active Myofascial Trigger Points. Arch. Phys. Med. Rehabil. 2008, 89, 16-23. [CrossRef] [PubMed]

37. Hsieh, Y.-L.; Yang, S.-A.; Yang, C.-C.; Chou, L.-W. Dry Needling at Myofascial Trigger Spots of Rabbit Skeletal Muscles Modulates the Biochemicals Associated with Pain, Inflammation, and Hypoxia. Evid.-Based Complement. Altern. Med. 2012, $2012,1-12$. [CrossRef] [PubMed] 
38. Cerezo-Téllez, E.; Torres-Lacomba, M.; Fuentes-Gallardo, I.; Perez-Muñoz, M.; Mayoral-del-Moral, O.; Lluch-Girbés, E.; PrietoValiente, L.; Falla, D. Effectiveness of dry needling for chronic non-specific neck pain. Pain 2016, 157, 1905-1917. [CrossRef]

39. Mansfield, C.; Vanetten, L.; Willy, R.; Di Stasi, S.; Robert, M.; Briggs, M. The effects of needling therapies on muscle force production. A systematic review and Meta-Analysis. J. Orthop. Sports Phys. Ther. 2018, 49, 154-170. [CrossRef] [PubMed] 